\title{
Dos cafés, una cultura urbana (Lugares del "Polo Bamba" y el "Tupí-Nambá": los hermanos San Román)
}

\begin{abstract}
Pablo Rocca*
Resumen:

A partir de la experiencia de dos inmigrantes españoles que sostuvieron, a lo largo de muchos años en el cruce de los siglos XIX y XX, dos cafés, donde se reunió gran parte de la vida cultural montevideana, este artículo examina la dimensión cultural de la tertulia y del café más allá de la anécdota a la que las crónicas de época habitualmente nos tienen acostumbrados.
\end{abstract}

\section{Palabras-clave:}

Cafés; Literatura y vida cultural; Montevideo

\section{De la anécdota al campo de trabajo}

Quisiera llamar la atención sobre el Café, ${ }^{1}$ un factor que hacia el Novecientos en las ciudades latinoamericanas empieza a desbordar las prácticas y los discursos culturales $y$, en consecuencia, altera el lugar mismo de los bienes simbólicos en ese campo así como sus formas de circulación material. Pero, para pisar firme, será necesario un rodeo previo.

Con la revolución liberal, en el siglo XVII, se origina el concepto de "opinión pública", denominación que pasa a abrazar todo un dominio de instituciones sociales (clubes, diarios, Cafés, revistas), a partir de los cuales la burguesía en ascenso postula el libre y equitativo intercambio del discurso, y a través de los que consigue legitimarse como fuerza política (HABERMAS, 1994). Para que esa "opinión pública" pudiera cimentarse, por toda Europa se tuvo que multiplicar el Café, donde el canje de las ideas adquirió una intensidad productiva mayor a la que mostraba en otros espacios difusores de la novedosa socialización. Desde entonces, en Europa se hizo posible caminar hacia la autonomización del campo cultural, y la irrupción de la figura del intelectual fuera del territorio sociodiscursivo del Estado, meta que pudo alcanzarse a mediados del siglo XIX. En América Latina el proceso fue más lento. A pesar del gran esfuerzo de mimetismo con las sociedades europeas, "la modernización, en todos sus aspectos fue -y continúa siendo- un fenómeno muy desigual" (RAMOS, 1989, p. 12). ${ }^{2}$

Nada más ilustrativo de estos desencuentros que hacia fines del siglo XVIII sólo

* Prof. Doctor, Universidad de la República, Uruguay

${ }^{1}$ Un poco arbitrariamente, para asignarle mayor relevancia visual y ejercer cierta violencia personificante, digamos, consigno con mayúsculas este vocablo que no sólo viene a aludir al espacio de reunión sino que busca constituirse en una metonimia de sus contertulios.

2 En virtud de estos desequilibrios, Julio Ramos propone explorar en el siglo XIX latinoamericano "/a literatura como un discurso que intenta autonomizarse", y analizar "las condiciones de imposibilidad de su institucionalización". 
en Londres había más de tres mil Cafés (EAGLETON, 1991, p. 7), mientras setenta años más tarde, una guía de Montevideo publicada por Jean Jacques Liefrink da cuenta de una nómina de 130 establecimientos del ramo (BARRIOS PINTOS, 1973, p. XIX). Contra lo que puede suponerse, las asimetrías no eran sólo de escala o de densidad demográfica. Otros factores para la diferenciación del campo cultural debieron cumplirse: la aparición del artista independiente de la política, la especialización profesional, la conquista de medios y de públicos. ${ }^{1}$ En las ciudades de nuestra modernidad descompensada, desde los albores del siglo XIX el Café vino a cumplir la misma función dinamizadora que en París o en Londres. Pero nunca tuvo tanta fuerza como a comienzos del siglo $\mathrm{XX}^{2}{ }^{2}$ cuando se convirtió en un elemento decisivo para la constitución del campo literario, transformándose en refugio primordial de los intelectuales y no apenas un marco para el esparcimiento o la charla menuda, donde quemar las muchas horas muertas durante la Colonia o de la primera independencia. ${ }^{3}$

En el Novecientos, los Cafés fueron territorios en pugna o en tensa vecindad. El primer tipo, recibió a un público en franca pelea con el establishment: el artista bohemio, el militante ácrata, a quienes las triunfantes evocaciones adormecedoras han tratado de recrear como sujetos excéntricos e inofensivos al sistema, finalmente amansados por la ponderación de la edad madura. El segundo tipo fue capaz de acoger un amplio espectro de clases y de grupos, muchas veces antagónicos, siempre estableciendo ubicaciones para unos y otros -como si se tratase de un pacto jurisdiccional-, todos moderados por la sabiduría amortiguadora del propietario. Las crónicas y los testimonios sobre este período reconstruyen esa geografía del Café montevideano del Novecientos: la mesa de los poetas decadentes, la de los burócratas, la de los obreros de tal o cual gremio, la de los miembros de este o aquel segmento burgués, la de los músicos, la de los actores al término de la puesta en escena. En estos ámbitos se desarrolló una performance compuesta por una dramatización de gestualidades, indumentarias características, entradas y salidas más o menos estudiadas de algunos parroquianos. Esto se fijó en la memoria y hasta se reprodujo de generación en generación.

Para estudiar la incidencia del Café en la cultura urge convertir la evocación anecdótica en campo de trabajo, el mito en espacio de reflexión. Esta sería la premisa fundamental. Hasta donde sabemos, en el Río de la Plata se sigue recorriendo estos núcleos de encuentro cultural en las fronteras de la memoria parcial o de la nostalgia. ${ }^{4}$ Esas piezas de la memoria son fuentes destacadas, a

\footnotetext{
${ }^{1}$ Sobre la noción de campo cultural y sus derivaciones (campo intelectual, campo literario, etcétera), cfr. Pierre BOURDIEU. Las reglas del arte, 1992/1997. Con todo, hay que prevenirse sobre el traslado excesivamente mecánico del concepto a la situación latinoamericana o, si se quiere, más específicamente rioplatense o aun montevideana.

2 Para repasar el problema, además del fundamental folleto citado de Aníbal Barrios Pintos, véase Alejandro MICHELENA, Los Cafés montevideanos, 1986 y Pablo ROCCA, Montevideo Altillos Cafés Literatura, 1991.

${ }^{3}$ Formas de la sociabilidad rústica no faltaron en estos territorios, ni siquiera en la campaña, donde los centros de encuentro llamados "pulperías" -comercios que alternaban la venta de alimentos con el despacho de bebidas- se multiplicaron desde el siglo XVII. Cfr. Aníbal BARRIOS PINTOS, "Pulperías de la Cisplatina", 1963, p. 175-206.
} 
veces ricas y hasta disfrutables, y de ellas puede extraerse alguna piedra preciosa para el análisis. Alguien que durante la primera mitad del siglo XX fue asiduo de cuanto Café, boliche, fonda y vinería montevideanas, alguien que dejó la mayor cantidad de apuntes memoriosos sobre estos locales de socialización, el escritor Manuel de Castro, intuyó que debían ser entendidos de otra manera:

mis frecuentaciones en el Café Tupí Nambá con Alberto Zum Felde y Eduardo Dieste, influyeron poderosamente en mi formación intelectual. Alrededor de estas dos figuras de las letras, muchos poetas jóvenes de aquella época, trabajábamos con fervor en una especie de noble emulación. Los cenáculos eran centros de actividad intelectual y no perdederos de tiempo. ${ }^{5}$

El Café vino a ser, de ese modo, la ruidosa trinchera donde se abroquelaron los intelectuales del Novecientos, los primeros que pretendieron vivir de lo que hacían, rebelándose -como ha dicho Ángel Rama- "contra un sistema socio-económico que no concedía ningún lugar al artista" (RAMA, 1985, p. 121). Allí se hacían lecturas en alta voz, se escribía entre el vocerío y el humo del tabaco. Desde allí se salía hacia el periodismo, la polémica, la exposición de pintura en salones para cofradías, a las mismas que estaba destinado el libro. ${ }^{6}$ Toda esta agitación, como en un reflujo de olas, tornaba al Café, donde volvía a ser discutida, criticada o silenciada. Por eso, cuando la letra hegemoniza la cultura, y cuando las clases medias empiezan a apropiarse de esa herramienta, el Café es el foro y el taller. No por azar esto sucede entre 1890 y 1910 cuando -como dice Martin Lyons-, se vive la etapa de oro del impreso y la lectura con "la primera generación que accedió a la alfabetización masiva, que también fue la última en considerar al libro como un medio de comunicación que no tenía que rivalizar ni con la radio ni con los medios de comunicación electrónicos del siglo XX" (LYONS, 1998, p. 476).

Hace dos décadas Robert Darnton advertía sobre la urgencia de "reconstruir el contexto social de la lectura". Para el cumplimiento de ese programa -que en Uruguay sigue siendo un inmenso vacío-, Darnton proponía que no había que limitarse a los aportes diversos de la teoría literaria sobre la obra y el lector, sino que era menester prestar oído a los pasos que llevan el objeto libro a su consumidor. Dicho de otro modo: antes del abordaje hermenéutico de un texto, cualesquiera sean las perspectivas, conviene revisar los factores materiales que hicieron posible ese objeto (el libro) y las que modelaron a su destinatario (el lector). Porque si estos elementos básicos son olvidados, podría caerse en una

\footnotetext{
${ }^{4}$ Con excepción de estos trabajos pioneros, aunque parciales: Jorge B. RIVERA, La bohemia literaria, 1981. Ángel RAMA, Las máscaras democráticas del modernismo, 1985, p. 116-124.

5 Ángel RAMA, "Encuesta literaria de Marcha: Respuesta de Manuel de Castro", 1960, p. 31. Una selección de crónicas sobre el tema: Manuel de CASTRO, La vida bohemia (Cronicones montevideanos), 2005. El archivo de Manuel de Castro está depositado en Sección de Archivo y Documentación del Instituto de Letras (SADIL, FHCE, UDELAR), desde 2004.

${ }^{6} \mathrm{Si}$ es que el libro llegaba a publicarse, ya que se multiplican por decenas los escritores de revistas y de periódicos. Prueba de la sinergia entre periodismo, literatura y Café son las polémicas mantenidas por los miembros de la minoría cultural de esa modernidad emergente. Sobre el caso uruguayo véase los textos reunidos en Pablo ROCCA, 2001
} 
suerte de metafísica de la lectura. La instigante propuesta de Darnton abría el camino para estudiar el "circuito de comunicación que va del autor al editor (si no al librero que asume ese papel), al impresor, al distribuidor, al vendedor, para llegar al lector".7

Quisiera dar un pequeño paso más, y proponer que no sólo se lee o se aprende a leer o a ver pintura o a escuchar música por la formación académica que pudimos recibir. Propongo que cuando el Café se vuelve una institución del sistema cultural, se empieza a leer de "oídas", es decir, por lo que otros cuentan, sugieren, enseñan a conocer y a pensar. Muchos libros fueron "leídos" de este modo, muchas películas y obras de teatro "vistas" y recordadas, mucha música y mucha política "aprendida" de una voz ajena o de un conjunto voces otras en la dialéctica oral del Café. En una cultura de fuertes tonalidades autodidácticas, ese capital simbólico se integra al sujeto, que se forma complementaria o adversativamente a los saberes académicos.

2. Dos vueltas de tuerca: los hermanos San Román

En un artículo de 1920 que luego refundió en Proceso intelectual del Uruguay (1930) (ZUM FELDE, 1920), Alberto Zum Felde advirtió que en el traspaso de los siglos anteriores nació el "intelectual de Café", y que el "Polo Bamba" fue la capital del estremecimiento nuevo:

[La] clientela [del "Polo Bamba"] llegó a componerse casi exclusivamente de escritores, poetas y propagandistas [...] en torno a cuyas mesas de mármol se reunían noche a noche, a discutir arduos temas de sociología o de estética, los jóvenes en quienes había brotado con encendido brío, la semilla de las ideas revolucionarias. (ZUM FELDE, 1967, II, p. 31)

La moral burguesa ordenaba que las mujeres se detuvieran en la puerta de tan peligroso recinto. Esta censura fue quebrada por la anarquista española Juana Buela, quien concurría a la mesa de sus compañeros en el "Polo Bamba", antes o después de participar en alguno de los numerosos círculos anarquistas que pululaban por Montevideo hacia 1900 (ZUBILLAGA, 1988, p. 11-39). Unos años después, hasta en el más "serio" Café "Tupí-Nambá" no era bien visto el ingreso de una mujer, algo que cotidianamente desafió la jovencita Blanca Luz Brum, "la única poetisa que se animaba a entrar sola al Café, siempre mordisqueando un membrillo, y en pos de Parra del Riego, con quien estaba de novia". Con todo, y si le creemos al narrador- testigo, la osadía de la poeta no era tanta porque iba en su condición de mujer de. ${ }^{8}$ Sea como fuere, en el ciclo que nos importa

7 Cito -y retraduzco- de Robert DARNTON, O beijo de Lamourette. Mídia, cultura e revolução, 1991, p. 112. Los estudiosos de la historia de la lectura han llamado además la atención sobre los lugares en que esta se ejerce (bibliotecas públicas y privadas, clubes sociales, etc.) y sobre la función del periodismo y de sus agentes materiales (desde los tipógrafos a los linotipistas). Véase, al respecto, Armando PETRUCCI, "Bibliotecas y lectura: entre progreso y conservación", 1999. Marc BARATIN y Cristian JACOB, O poder das bibliotecas, 2000. La cuestión ha ocupado a un equipo nutrido y competente de investigadores en Brasil más que en cualquier otra parte de América Latina. En este campo son fundamentales los trabajos reunidos en Márcia ABREU, Leitura, história e história da leitura, 2000. Márcia ABREU e Nelson SCHAPOCHNIK, Cultura letrada no Brasil: objetos e práticas, 2005. Debo al doctor Schapochnik el conocimiento de estos aportes sobre el punto. 
detenernos, entre 1900 y 1915, las fotografías supervivientes de las mesas de estos dos Cafés montevideanos sólo muestran grupos de hombres con mostachos de puntas alzadas, trajes oscuros, corbatines, sombreros aludos o galeritas, y cigarrillos casi unánimes. La mayoría de los retratados en este período son escritores, músicos, pintores. Y contrariamente a lo que ha dicho Alfredo Mario Ferreiro, y se ha repetido, no por obra de ningún "misterio" después de 1904 en el Café dominaron los intelectuales. ${ }^{9}$ Justamente porque esa era su hora histórica, y ese su único dominio.

Los dueños de esos dos Cafés emblemáticos del Novecientos, los hermanos Severino y Francisco San Román, llegaron a Montevideo en el año 1872. Los dos habían nacido en 1861 en Santa Eulalia de Camos, Ayuntamiento de Nigrán, en Valle Miñor. Radicados en Montevideo, donde hicieron su vida, su familia y su trabajo, Francisco morirá en 1932 y Severino en 1941. ${ }^{10}$ Antes de echar raíces en la capital uruguaya, Francisco trabajó unos años en el estado de Santa Catarina (Brasil), donde "había sido empleado de casas que se ocupaban de la manipulación del aromático grano". ${ }^{11}$ Es harto probable que su hermano lo haya acompañado, pero no pudimos corroborar este dato, que por lo tanto queda en el campo de la hipótesis. ${ }^{12}$

El "Polo Bamba" se inauguró el 25 de julio de 1885, fundado por Francisco San Román en la calle Colonia Nos. 6 y 8. Cuatro años después, Francisco se lo vendió a su hermano Severino. El escritor y periodista Alberto Lasplaces, quien llegó a concurrir a este Café en los últimos tiempos, observa que esa ubicación entre las calles Florida y Ciudadela le permitía atraer numeroso público, ya que estaba en un enclave fundamental: "a pocos metros de la Plaza Independencia, cerca de la Casa

8 Sobre la presencia de Juana Buela en el "Polo Bamba", véase Aníbal BARRIOS PINTOS, 1973, pp. XII-
XIII. La referencia a Blanca Luz Brum en Manuel de CASTRO, "Cafés y cenáculos literarios en un cuarto
de siglo (1918-1945)", p. 136. Originalmente en "El País", Montevideo, setiembre de 1959. De fines de
los años veinte debe ser el recuerdo un poco deshilachado de este mismo cronista, quien evoca el pasaje
circunstancial de la escritora española Mercedes Pinto por su mesa del "Tupí-Nambá" (Manuel de CASTRO,
"Evocaciones del Viejo Tupí", p. 36. Originalmente en "La Mañana", Montevideo, 18 de febrero de 1956).

${ }^{9}$ Alfredo Mario FERREIRO, "El «Polo Bamba» se vino desde la calle Colonia hasta la Plaza Independencia para mostrarle a Montevideo la sin par calidad de su clientela", en "La Razón", Montevideo, 23 de enero de 1945, p. 1 y 6 . La reiteración de esta invocación al misterio, sin referir la fuente, en Aníbal BARRIOS PINTOS, op. cit., p. XXII.

${ }^{10}$ Los datos precisos sobre la fecha y el lugar de origen de Francisco San Román, en Carlos ZUBILLAGA, "Galicia y los gallegos en la cultura uruguaya", 1997, p. 13, n. 6. La fecha de su muerte, ocurrida el lunes 22 de febrero de 1932, en Aníbal BARRIOS PINTOS, op. cit., p. XXVI. Por gentileza del profesor Alción Cheroni, bisnieto de Severino San Román, entré en contacto con otros descendientes directos: la señora Gladys San Román, quien me conectó con su primo, el señor Severino San Román. Según información que maneja sobre su homónimo ancestro, este habría nacido en el mismo lugar que Francisco, también en el año 1861, aunque no pudo precisarme el día y el mes. De ser exacto este dato, es razonable pensar que fueran mellizos. La muerte de don Severino ocurrió en diciembre de 1941, según Alberto LASPLACES, art. cit.

${ }^{11}$ SIN FIRMA, "Mañana cumple años el Café Tupí Nambá", en "El Plata", Montevideo, 7 de mayo de 1927, en Autores Varios, Tupí \& Nambá. F. San Román e hijos. Montevideo, s/e, 1927, p. 35. En el texto citado, Zubillaga da una versión levemente diferente a la este cronista anónimo: en Brasil, Francisco se desempeñó "en una fazenda y casa exportadora de café de Santa Catarina". Nada informa sobre Severino en estos menesteres (loc. cit).

${ }^{12}$ Al día de la fecha (24 de julio de 2006), en el aparentemente todopoderoso universo de internet, hallé sólo dos referencias a Severino San Román, que glosan superficialmente lo dicho por Zum Felde en su libro citado de 1930. 
de Gobierno, de las Cámaras Legislativas, de los teatros Solís y Urquiza y de las redacciones de los diarios El Día, El Siglo, La Razón y El Tiempo, que constituían a prensa metropolitana de aquella época". Mejoró su situación en los primeros años del siglo XX, cuando se mudó a un local "más adecuado y más estratégicamente colocado, en la esquina de la Plaza Independencia y calle Ciudadela", donde en 1914 cerró definitivamente. Estaba en "una casa vieja de dos pisos, bastante abandonada, [que tenía] un amplio salón que se abría en amplios ventanales [...] por los que se veía todo lo que pasaba afuera" (LASPLACES, 1941). ${ }^{13}$ En esta última locación, el "Polo Bamba" alcanzó la plenitud de la bohemia y el seguro camino hacia la ruina económica. Manuel de Castro lo ha reconstruido con la dorada memoria de un tiempo pasado que, para el cronista, siempre fue mejor:

el viejo Polo-Bamba [tenía] bulliciosas tertulias ideológicas y estéticas, salpicadas con la lectura de los dramas de su dueño Severino San Román, con menoscabo del consabido chocolate con que obsequiaba a sus auditores. [Allí] el poeta Ángel Falco, uno de los iniciadores de la llamada "poesía social" en el Uruguay, con sus mostachos mosqueteriles, la corbata volandera, el sombrero de amplias alas y una flor roja en el ojal, representaba el afiche del bardo revolucionario, lo que no le impedía, desdoblando su personalidad, componer sonetos amorosos para su Breviario galante. (DE CASTRO, 1955, p. 20-21)

Lasplaces describe el Café de un modo más verosímil (o menos "literario") que Zum Felde y Manuel de Castro, identificando en ese amplio salón iluminado tres regiones distintas: la de los poetas, al Este; la de los anarquistas, al Sur y, en el centro, "el país de los tranquilos burgueses [...] que bebían su café a pequeños sorbos, sin asustarse, sin alarmarse jamás".

La desmesura se atemperaba en el "Tupí-Nambá", que Francisco San Román abrió al público el 8 de mayo de 1889 en la esquina de Buenos Aires y Juncal, con frente al Teatro Solís. Una exacta semana después de su apertura, un periodista del diario El Popular, le preguntó: "Diga, Sr. San Román, en qué librajo encontró usted el título con que ha bautizado su café?". Y obtuvo la siguiente respuesta: "iLibrajo! Está usted equivocado. Oiga usted: Los Tupí Nambá fueron tribus oriundas del Brasil, en la provincia de Bahia, bravos guerreros que unidos pelearon por su suelo, hasta que fueron dominados por los portugueses...". Como muestra suplementaria de erudición, Francisco San Román recomienda la lectura del capítulo 28 del libro Indígenas americanos, de Hans Staden, y cita cuatro versos del poema "I Juca Pirama", del romántico brasileño Antônio Gonçalves Dias, que el periodista transcribe en un errático portugués. ${ }^{14}$ Pese a esta respuesta que no parece anunciar la existencia de un pragmático empresario, Francisco San Román manejó su negocio con habilidad y pericia. En lugar de privilegiar a los clientes fragorosos y poco lucrativos, mantuvo un clima más reservado. Algo de esto notó el andaluz montevideano José Mora Guarnido, testigo de su última hora, quien

\footnotetext{
${ }^{13}$ Ignoramos a qué otra actividad se dedicó Severino, si es que no se acogió a la jubilación. Como sea, para la fecha de cierre del "Polo Bamba" -si es que la fecha de 1861 es la correcta para su nacimientotenía 53 años. Y tendría tres décadas de vida por delante
} 
lo calificó como "un hombre amplio y cortés, pero práctico" (MORA GUARNIDO, 1991 , p. 108). ${ }^{15}$ Su mirada vigilante le permitía estar "en todas partes impuesto de todo lo que ocurre por todo un estado mayor de mozos y dependientes, que a su autoridad superior ocurren en consulta", como se lee en una crónica del diario Época de 1892 (BARRIOS PINTOS, 1973, p. XXIV). En cambio, Severino se adosaba a las discusiones sobre la filosofía de Marx o de Bakunin, o estimulaba a los hacedores de versos, y él mismo solía treparse a una silla y recitaba pasajes de alguna de sus cuatro piezas dramáticas, que llegó a editar en sencillos y delgados folletos (SAN ROMÁN, 1913-1914-1922). ${ }^{16}$ Así, sus balances tenían que cerrar con déficit.

En efecto, mientras languidecía el "Polo Bamba", el "Tupí Nambá" se vigorizaba. ${ }^{17}$ Tanto que, luego de un trimestre de cierre por reparaciones, el 12 de abril de 1912 reabrió sus puertas totalmente renovado, inaugurando otra entrada por Juncal y mucho más, según una nota aparecida en La Razón de Montevideo:

Del antiguo café no queda más que el local. Todo lo demás es nuevo y magnífico. Lo visitamos esta tarde y quedamos sorprendidos de lo que San Román ha hecho allí. Nada de lo que hemos visto en la capital argentina o brasilera puede igualarse. Es un café único en esa parte del continente sudamericano. El principal salón ha sido decorado a estilo Imperio. [...] El otro salón, de mayor amplitud que el antiguo, tiene un color claro, que contrasta con el primero, poniendo una nota de alegría en el conjunto del decorado. Los frisos constituyen un detalle artístico, tanto en una como en la otra sala. [...] El cristal abunda, en los espejos, que se multiplican a lo largo de las paredes, en las mesas, en las puertas y ventanas, en el mostrador, etc., etc. ${ }^{18}$

Contrasta este lujo con la abrumada casa que ocupaba el "Polo Bamba", lo que habla de un comercio que no era mantenido por bolsillos flacos, sino por una oferta diversificada y que pretende capturar la atención de los que sí pueden conversar menos y pagar más. Como si fuera una metáfora del Uruguay batllista, el "TupíNambá" era un espacio democratizador de la convivencia de diferentes tribus. Hasta en el propio don Francisco se podría concentrar esa tolerancia moderatista: "Yo que soy blanco -solía decir-, he tenido la honra de servirle muchas veces el café a don José Batlle y Ordóñez". ${ }^{19}$ En setiembre de 1926 abandonó ese local al que, desde entonces, todo Montevideo pasó a denominar el "Tupí Viejo". Aun

14 Cfr. Tupí \& Nambá..., p. 7-8.

15 Originalmente en "Revista Nacional", Montevideo, no 202, octubre-diciembre 1959.

16 Todas estas publicaciones, sin constancia de casa editorial, seguramente fueron financiadas de su peculio.

17 No hay espacio aquí para tratar los Cafés y las fondas alternativas a la bohemia desenfrenada del "Polo Bamba", aunque conviene recordar al "Sarandí" y, sobre todo, al "Británico", fundado en 1914, el mismo año que desaparece el "Polo Bamba" $y$, previsiblemente, heredero de sus parroquianos. Para mayor información véanse los libros antes citados.

18 SIN FIRMA, "La renovación del Tupí-Nambá", en "La Razón", Montevideo, 12 de abril de 1912. Incluido en Autores Varios, Tupí \& Nambá..., 1927, p. 23-24. 
desprovisto del aura de su predecesor, el "Tupí Nuevo" de 18 de julio entre Rio Branco y Herrera y Obes, no obstante ocupó un local palaciego, "de buen gusto, confort y riqueza decorativa". ${ }^{20}$ Cerró en 1959, y pronto reabrió en Colonia entre Rio Branco y Convención. Pero fue una mera supervivencia, ya que perdió el brillo de antaño, y se fue apagando hasta desaparecer en 1968. También en esta última frontera parece regir la metáfora: nacido y crecido en tiempos de progreso, prudencia y tolerancia, el "Tupí" se despeña violentamente junto con el país.

Los hermanos San Román fueron como las dos caras posibles de la misma dinámica cultural. Francisco, el sensato comerciante que acoge a los artistas siempre y cuando no espanten a los clientes más convencionales; Severino, el aspirante a intelectual, que se formó como tal -y como pudo- en las tertulias que él mismo prohijó. El "Tupí" obtendría el reconocimiento de las autoridades municipales en $1926,{ }^{21}$ y hasta Francisco y sus herederos buscarían escribir una historia oficial espigando las crónicas más amables que se les había dedicado, juntándolas en un elegante folleto el mismo año en que dejaron su lujoso local. El Café de Francisco San Román gozaría también del beneplácito retrospectivo de los intelectuales que lo habían frecuentado. Al revés, cuando los antiguos clientes del "Polo Bamba" autoevaluaban su juvenil radicalismo con un dejo irónico, este Café pasa a ser objeto de la recordación casi folclórica, en el borde de la piedad y la parodia. Con mejor eficacia que nadie, esta perspectiva la representa Alberto Zum Felde:22

Un propietario celoso de su negocio, trataría de ahuyentar a tertulianos tan poco convenientes; pero el viejo Severino, como todos llamábanle familiarmente, era uno de los más animados contertulios de su propia parroquia. Encantado de respirar aquella atmósfera cargada de electricidad mental, iba de un grupo a otro, participando de las discusiones, escuchando las lecturas, emitiendo sus opiniones absurdas, prodigando sus frases funambulescas. Porque Severino hizo de la incongruencia el cetro de su reino extraño. Escribía y leía dramas en los que el disparate llegaba a convulsionar de risa a los oyentes. [...] Con frecuencia, subido sobre una mesa, arengaba a los concurrentes con discursos inverosímiles, que en su lenguaje llamaba pelipondias, entre aplausos y carcajadas. (ZUM FELDE, 1967, p. 35-39) 23

\footnotetext{
19 Testimonio de José MORA GUARNIDO, art. cit, p. 109.

20 "Acompañó a don Pancho desde la fundación del «Tupí-Nambá» hasta el año 1911, en que se retiró de los negocios, su sobrino don Casiano Estévez. Socio leal, trabajador, honrado y lleno de iniciativas, fue durante todo ese tiempo su brazo derecho. Y hoy mismo, apartado ya de las actividades comerciales, sus consejos de hombre experimentado no dejan de pesar en la buena marcha de la casa. Debemos citar, también, en estricta justicia, a los actuales socios de don Pancho, sus hijos Francisco, Juan José y Luis María. Activos, laboriosos e inteligentes, han heredado las mejores condiciones de su padre y son invalorables auxiliares de este, por su identificación absoluta de ideas y la compenetración mutua que entre ellos existe" (Sin Firma, "Mañana cumple años el Café Tupí Nambá", en "El Plata", Montevideo, 7 de mayo de 1927, en Autores Varios, Tupí \& Nambá..., 1927, p. 37-38). Una lista de los empleados más antiguos de la casa, la mayor parte de ellos de origen gallego, en Aníbal BARRIOS PINTOS, 1973, p. XXV.

${ }^{21}$ Un diploma otorgado por el Concejo de Administración de Montevideo, el 24 de setiembre de 1926, le reconoce a Francisco San Román e hijos, su "elevado espíritu progresista", con el que "han incorporado a los valores edilicios de la ciudad una obra de positivo mérito cultural". La reproducción facsimilar de este diploma en Tupí \& Nambá..., 1927, s/n.

22 Dandy y anarquista hasta las márgenes de la veintena, batllista orgánico desde su precoz madurez y católico progresista en la ancianidad.
} 
No pretendo reivindicar en Severino San Román a un Alfred Jarry hispano-criollo ni apreciarlo como si fuera el atrevido protosurrealista Jacques Vaché. Ni siquiera postularlo para el panteón nacional. Está claro que no fue un escritor muy apto, y un rápido ejemplo puede mostrarlo. La familia oriental, brevísima pieza que subtituló "drama histórico nacional en tres actos", de 1913, moviliza más de dos decenas de personajes, que se acumulan sin mucho concierto. El lenguaje dramático tropieza de continuo con inconsecuencias y la introducción de una cadena de deux ex machina, que fracturan lo verosímil. Sin embargo, aunque no logre el adecuado ajuste expresivo, hay una pretensión joco-burlesca que podría fundar estos quiebres y que, por el absurdo, conecta el discurso de San Román con las propuestas más sofisticadamente provocativas de su época y su contorno. Si se contrasta esta pieza con la carta-ultimatum de Roberto de las Carreras a Batlle Ordóñez, ${ }^{24}$ en la que lo emplaza a nombrarlo embajador en París o con el "Epílogo wagneriano de La política de fusión", en que Julio Herrera y Reissig se mofa de la rusticidad de los uruguayos, se verá que las diferencias de lenguaje son enormes (DE LAS CARRERAS, 1968; HERRERA Y REISSIG, 1998, p. 664697): donde los refinados modernistas encuentran el justo término y la frase alambicada, Severino coloca la palabra obvia, el ataque sin mediaciones. Pero, en sustancia, hay una común tarea demoledora de la moral filistea y burguesa: en los mencionados escritores de "buenas familias" late la nostalgia de un proyecto patricio que se derrumba, mientras que el inmigrante que ha adquirido en estas tierras nuevas el pleno sabor de la cultura letrada, está más cerca del futuro que del pasado. De ahí la práctica de una denuncia explícita del poder, que bien pudo aprender de las mesas ácratas de su Café. La familia oriental consiste en una cruda burla, más que en una elusiva parodia, del presidente Batlle y Ordóñez y los suyos. En rigor, el presidente aparece al principio de la obra como un hombre autoritario, rodeado de adulones -en especial de militares-, como si fuera un monarca absolutista, y de pronto se concentra en lograr la exclusiva felicidad de su hija. La sola trascripción del último aparte desnuda dónde quiere golpear el autor:

Aparece una joven simbolizando la Patria, rodeada de una junta de hombres honorables, de barba y cabellos blancos, colocándose á la derecha del Presidente. Todos los personajes miran con sorpresa esta escena. - El Presidente toma de la percha la banda y el bastón presidencial y se lo entrega á la joven que representa la Patria, colocándole la banda en el pecho y entregándole un ramo de flores. Todos los personajes ofrecen flores al Presidente. La Patria apoya su mano derecha en el hombro del Presidente. La orquesta ejecuta el

\footnotetext{
${ }^{23}$ En otro pasaje ilustrativo, alojado en la última edición (1967), y que por lo tanto sobrevivió a las últimas mutaciones ideológicas de ese autor-protagonista, Zum Felde dice: "Al «Polo Bamba» convergen la parroquia del Centro Internacional [de Estudios Sociales] y la de los cenáculos decadentes. Por sus veladas bohemias pasan casi todos los jóvenes de esa generación. Los más, pasan... perdiéndose después en el anónimo colectivo de la adaptación burguesa, cortados el pelo y los ideales por la misma tijera fría del desengaño; los menos, camino de una posteridad gloriosa" (p. 37).

${ }^{24}$ La mencionada carta insertada en el texto mayor, p. 121.
} 
Himno Nacional). TELÓN LENTO. (SAN ROMÁN, 1913, p. 31)

Tras la voz de Severino San Román se agitan, confusos, los combativos discursos anarquistas contra la parafernalia nacionalista y el intento de erosionar a quien las masas trabajadoras e inmigratorias perciben como el salvaguarda de sus intereses. Visto de este modo, no sólo por sus arranques histriónicos ni por su arte menor, el dramaturgo de Café podía ser despreciado y carnavalizado en el recuerdo nada cordial o no muy respetuoso de Zum Felde. En el fondo, la escritura del gallego -y comerciante al fin- que se autoerige en intelectual, subvertía un caro principio para la elite: el arte para los que saben; para los otros, los recién llegados al festín de la alta cultura, paciencia y barajar. ¿Quién, si no, iba a ocupar el lugar del espectador?

Nota: Una versión de este texto se publicó en el Anuario del Centro de Estudios Gallegos, Montevideo, Universidad de la República/ Facultad de Humanidades y Ciencias de la Educación/ Centro de Estudios Gallegos, 2006, p. 125-137.

\section{Bibliografia:}

ABREU, Márcia (org.), Leitura, história e história da leitura. Campinas/São Paulo: Mercado de Letras/Fapesp/ALB, 2000.

e SCHAPOCHNIK, Nelson (orgs.), Cultura letrada no Brasil: objetos e práticas. Campinas, Mercado de Letras/Fapesp/ALB, 2005.

AUTORES Varios. Tupí \& Nambá. F. San Román e hijos. Montevideo, s/e, 1927. BARATIN, Marc y JACOB, Cristian, O poder das bibliotecas. A Memória dos livros no Ocidente. Rio de Janeiro, EdUFRJ, 2000.

BARRIOS PINTOS, Aníbal, Pulperías y Cafés. Instituciones substanciales del vivir oriental. Montevideo, Ed. Acción, 1973.

BOURDIEU, Pierre, Las reglas del arte. Génesis y estructura del campo literario. Barcelona, Anagrama, 1997. (Traducción de Thomas Kauf). [1992]

CASTRO, Manuel de, La vida bohemia (Cronicones montevideanos). Montevideo, Banda Oriental, 2005 (Antología, prólogo y notas de Pablo Rocca).

. "Una vida henchida de interés al servicio del país: El editor Orsini Bertani

y la cultura uruguaya", en "Suplemento Femenino" de "La Mañana", Montevideo, 12 de junio de 1955.

DARNTON, Robert, O beijo de Lamourette. Mídia, cultura e revolução. São Paulo, Companhia das Letras, 1991. (Tradução de Denise Bottman).

DE LAS CARRERAS, Roberto, "Interview político con Roberto de las Carreras", en Psalmo a Venus Cavalieri y otras prosas. Montevideo, Arca, 1968. (Antología y prólogo de Ángel Rama). [1903].

EAGLETON, Terry, A função da crítica. São Paulo, Martins Fontes, 1991. (Tradução de Jefferson Luiz Camargo). [1984]

FERREIRO, Alfredo Mario, "El «Polo Bamba» se vino desde la calle Colonia hasta 
la Plaza Independencia para mostrarle a Montevideo la sin par calidad de su clientela", en "La Razón", Montevideo, 23 de enero de 1945.

HABERMAS, Jürgen. Historia y crítica de la opinión pública. La transformación estructural de la vida pública. México, Ed. G. Gili, 1994. (Versión castellana de Antonio Doménech con la colaboración de Rafael Grasa). [1962/ 1990].

HERRERA Y REISSIG, Julio, "Epílogo wagneriano de La política de fusión. Con surtidos de psicología sobre el imperio de Zapicán", en Poesía completa y prosas. Madrid, Alca XX/Scipione Cultural, 1998. (Edición crítica de Ángeles Estévez) [1909].

LASPLACES, Alberto, "Los cafés literarios: Recuerdos del «Polo Bamba»", en "Suplemento Dominical" de "El Día", Montevideo, No 466, 21 de diciembre de 1941.

LYONS, Martin, "Los nuevos lectores del siglo XIX: mujeres, niños, obreros", en Historia de la lectura en el mundo occidental, Guglielmo Cavallo y Roger Chartier (coordinadores). Madrid, Taurus, 1998 [1997].

MORA GUARNIDO, José. "Panorámica y postrimerías del Tupí-Nambá", en ROCCA, P. (ed.). Montevideo altillos cafés literatura. Montevideo, Arca, 1991.

PETRUCCI, Armando, "Bibliotecas y lectura: entre progreso y conservación", en Alfabetismo, escritura, sociedad. Barcelona, Gedisa, 1999.

RAMA, Ángel, Las máscaras democráticas del modernismo. Montevideo, Arca, 1985.

, "Encuesta literaria de Marcha: Respuesta de Manuel de Castro", en "Marcha", Montevideo, No 1.006, 29 de abril de 1960

RAMOS, Julio, Desencuentros de la modernidad en América Latina. Literatura y política en el siglo XIX. México, Fondo de Cultura Económica, 1989.

RIVERA, Jorge B., La bohemia literaria (Vol. 4 de La vida de nuestro pueblo. Una historia de hombres, cosas, trabajos, lugares). Buenos Aires, CEDAL, 1981.

ROCCA, Pablo (antología y prólogo), Montevideo Altillos Cafés Literatura. Montevideo, Arca, 1991.

(Recopilación, prólogo y notas), Polémicas literarias del Novecientos. Montevideo, Banda Oriental, 2001.

SAN ROMÁN, Severino. Obra dramática de Severino San Román: El chimpancé. Hoy amapola (Drama en cuatro actos). Montevideo, Imprenta Sans y Martínez, 1913. [Folleto de 36 págs.] La familia oriental (Drama histórico nacional en tres actos). Montevideo, Imprenta Sans y Martínez, 1913. [Folleto de 32 págs.] El Ilanto literario (Comedia dramática en cuatro actos). Montevideo, Imprenta Sans y Martínez, 1914. [Folleto de 36 págs.] Alma francesa (Comedia dramática en tres actos). Montevideo, Imprenta G.V. Marino, 1922. [Folleto de 38 págs].

ZUBILLAGA, Carlos. "Luchas populares y cultura alternativa en Uruguay. El Centro Internacional de Estudios Sociales", en "Siglo XX. Revista de Historia", Monterrey, No 6, Facultad de Filosofía y Letras - Universidad Autónoma de Nuevo León, juliodiciembre 1988.

ZUM FELDE, Alberto, "Crítica literaria: Tres épocas", en "El Día. Edición de la Tarde", Montevideo, 17 de junio de 1920. 
Proceso intelectual del Uruguay. Montevideo, Ediciones del Nuevo Mundo, 1967, II.

. "Galicia y los gallegos en la cultura uruguaya", en "Anuario del Centro de Estudios Gallegos", Montevideo, FHCE, UDELAR, 1997, p. 13, n. 6.

\section{Abstract:}

From the experience of two Spanish immigrants, who maintained along many years durings the turn of the nineteenth through the twentieth century, two cafés in which would happen a significant part of the cultural life of Montevideo, this essay examines the cultural dimensio of those gatherings and the café itself beyond the anecdotes that we grew familiar to thanks to the chronicles of that time.

\section{Keywords:}

Cafés, literature and cultural life, Montevideo 